\title{
Characterization of the 23S and 5S rRNA genes and 23S-5S intergenic spacer region (ITS-2) of Photobacterium damselae
}

\author{
Carlos R. Osorio ${ }^{1, *}$, Matthew D. Collins ${ }^{2}$, Jesús L. Romalde ${ }^{1}$, Alicia E. Toranzo ${ }^{1}$ \\ ${ }^{1}$ Departamento de Microbioloxía e Parasitoloxía e Instituto de Acuicultura,Universidade de Santiago de Compostela, \\ 15782 Santiago de Compostela, Galicia, Spain \\ ${ }^{2}$ School of Food Biosciences, University of Reading, PO Box 226, Whiteknights, Reading RG6 6AP, UK
}

\begin{abstract}
The 23S ribosomal RNA (rRNA) gene has been sequenced in strains of the fish pathogens Photobacterium damselae subsp. damselae (ATCC 33539) and subsp. piscicida (ATCC 29690), showing that 3 nucleotide positions are clearly different between subspecies. In addition, the 5S rRNA gene plus the intergenic spacer region between the 23S and 5S rRNA genes (ITS-2) were amplified, cloned and sequenced for the 2 reference strains as well as the field isolates RG91 (subsp. damselae) and DI21 (subsp. piscicida). A $100 \%$ similarity was found for the consensus 5S rRNA gene sequence in the 2 subspecies, although some microheterogeneity was detected as inter-cistronic variability within the same chromosome. Sequence analysis of the spacer region between the $23 \mathrm{~S}$ and $5 \mathrm{~S}$ rRNA genes revealed 2 conserved and 3 variable nucleotide sequence blocks, and 4 different modular organizations were found. The ITS-2 spacer region exhibited both inter-subspecies and intercistronic polymorphism, with a mosaic-like structure. The EMBL accession numbers for the 23S, $5 \mathrm{~S}$ and ITS-2 sequences are: $P$. damselae subsp. piscicida 5S gene (AJ274379), $P$. damselae subsp. damselae 23S gene (Y18520), subsp. piscicida 23S gene (Y17901), P. damselae subsp. piscicida ITS-2 (AJ250695, AJ250696), P. damselae subsp. damselae ITS-2 (AJ250697, AJ250698).
\end{abstract}

KEY WORDS: $23 \mathrm{~S} \cdot 5 \mathrm{~S} \cdot \mathrm{ITS}-2 \cdot$ Photobacterium damselae $\cdot$ Intergenic spacers Resale or republication not permitted without written consent of the publisher

\section{INTRODUCTION}

The species Photobacterium damselae includes Gram-negative marine bacteria belonging to 2 different subspecies, namely subsp. damselae and subsp. piscicida (Gauthier et al. 1995). P. damselae subsp. piscicida (formerly Pasteurella piscicida) is the causative agent of pasteurellosis or pseudotuberculosis, one of the most important fish diseases in marine aquaculture (Magariños et al. 1996). Strains of the bacterium are biochemically and serologically homogeneous, although minor variability has been detected by ribotyping analysis (Magariños et al. 1997), amplified fragment length polymorphism (AFLP) (Thyssen et al. 2000) and randomly amplified polymorphic DNA analysis (RAPD) (Magariños et al. 2000). P. damselae subsp. damselae (formerly Vibrio damsela) has been reported to cause wound infections and fatal disease in a variety of marine animals and humans (Morris et al. 1982, Clarridge \& Zighelboim-Daum 1985, Buck et al. 1991). These 2 subspecies are readily differentiated by phenotypic traits, including optimal growth conditions of temperature and salinity, motility, gas production from glucose and host range, as well as a number of enzymatic properties such as nitrate reductase, urease, lipase, amylase and hemolysis. Moreover, in contrast to subsp. piscicida, which is serologically homogeneous, at least 4 serotypes are recognized within $P$. damselae subsp. damselae (Fouz et al. 1992). In spite of this, the 2 subspecies of $P$. damselae show a high degree of overall genetic similarity as revealed by chromosomal DNA-DNA hybridization (Gauthier et al. 1995) and 
possess identical 16S ribosomal RNA (rRNA) gene sequences (Osorio et al. 1999). This similarity at the 16S rRNA gene level has precluded the design of subspecies-specific PCR-based probes for the detection of each subspecies in natural samples. Thus, additional phylogenetic information from these 2 subspecies is desirable in order to unravel their phylogenetic affinity, as well as to provide alternative DNA targets for molecular typing.

Sequence analysis of the rRNA operon (rrn) has proved to be a valuable taxonomic tool for bacterial classification and for phylogeny construction (Woese 1987). 16S rRNA gene sequencing has been extensively employed for taxonomic purposes at the species level or above, and 23S and 5S rRNA gene sequencing used to a much lesser extent. rRNA gene sequences are relatively highly conserved at the species and subspecies levels. However, the intergenic transcribed spacer regions (ITS), located between the $16 \mathrm{~S}$ and 23S (ITS-1) and 23S and 5S (ITS-2) ribosomal genes, are thought to be under less evolutionary pressure and, therefore, may provide greater genetic variation than rRNA genes. The number of $r r n$ operons in bacteria varies from 1 to 15, and thus genetic variations in ITS regions are not only inter-strain, but also intercistronic. These characteristics make ITS regions a potentially valuable tool for taxonomic and typing purposes, and their use as such has received increased attention in recent years (Barry et al. 1991, Gürtler \& Stanisich 1996). The aim of the present study was to characterize the 23S and 5S rRNA genes, as well as the ITS-2 region, at the DNA sequence level in strains of the 2 Photobacterium damselae subspecies.

\section{MATERIALS AND METHODS}

Bacterial strains. Photobacterium damselae subsp. damselae strains (RG91, from Scophthalmus maximus,
Spain; ATCC 33539, from Chromis punctipinnis, USA) and subsp. piscicida strains (DI21, from Sparus aurata, Spain; ATCC 29690, from Seriola quinqueradiata, Japan) were grown aerobically on Tripticase Soy Agar plates at $25^{\circ} \mathrm{C}$. Bacteria were stored at $-70^{\circ} \mathrm{C}$ in Tripticase Soy Broth supplemented with 15\% (vol/vol) glycerol.

DNA extraction and PCR. Genomic DNA was extracted as described previously (Osorio et al. 1999). PCR products and plasmid DNA were purified respectively with the QIAquick PCR purification Kit and QIAprep Spin Miniprep Kit (QIAGEN), following the manufacturer's recommendations.

The primers used in this study are described in Table 1. Amplification of the 23S rRNA gene was carried out as follows: denaturation at $95^{\circ} \mathrm{C}$ for $4 \mathrm{~min}$, followed by 30 cycles of $95^{\circ} \mathrm{C}$ for $1 \mathrm{~min}, 55^{\circ} \mathrm{C}$ for $1 \mathrm{~min}$, and elongation at $72^{\circ} \mathrm{C}$ for $3 \mathrm{~min}$. For amplification of ITS-2 and the 5S rRNA gene, PCR was carried out as follows: denaturation at $95^{\circ} \mathrm{C}$ for $4 \mathrm{~min}$, followed by 30 cycles of $95^{\circ} \mathrm{C}$ for $1 \mathrm{~min}, 60^{\circ} \mathrm{C}$ for $1 \mathrm{~min}$, and elongation at $72^{\circ} \mathrm{C}$ for $1 \mathrm{~min}$. A final step of $72^{\circ} \mathrm{C}$ for $10 \mathrm{~min}$ was included for chain completion in all the reactions.

Cloning of PCR products and DNA sequencing. PCR products were cloned using the TOPO-TA Cloning Kit (Invitrogen), following the manufacturer's instructions. The DNA sequence was determined by the dideoxy chain termination method on either plasmid or PCR product templates using the Taq DyeDeoxy terminator cycle sequencing kit (Applied Biosystems) and an ABI 373 automated sequencer (Applied Biosystems). Primers complementary to both $5^{\prime}$ and $3^{\prime}$ ends of the inserts were used for sequencing reactions. For 23S rRNA gene sequencing, additional primers were designed for gene walking (Table 1).

Analysis of sequence data. Closest relatives of the sequences were determined by performing EMBL database searches with the FASTA program (Pearson \& Lipman 1988). Phylogenetic trees were constructed

Table 1. Photobacterium damselae subsp. piscicida. Oligonucleotides used in this study. Position refers to the 16S rRNA gene (EMBL accession no. Y18496) and 23S rRNA gene (EMBL accession no. Y17901) of Strain ATCC 29690

\begin{tabular}{|c|c|c|c|}
\hline Oligonucleotide & Sequence & Position & Application \\
\hline $23 \mathrm{~S}-5^{\prime}$ & 5'-GGTGGATGCCTTGGCA-3' & $23 \mathrm{~S}(23-38)$ & 23S amplification \\
\hline $23 \mathrm{~S}-3^{\prime}$ & 5'-TTCCCGCTTAGATGCTTTC-3' & $23 \mathrm{~S}(2754-2736)$ & 23S amplification \\
\hline $23 \mathrm{~S}-5^{\prime}-\mathrm{II}$ & 5'-TATCCTGTCTGAATATGGG-3' & $23 \mathrm{~S}(379-397)$ & $23 \mathrm{~S}$ sequencing \\
\hline $23 \mathrm{~S}-5^{\prime}-\mathrm{III}$ & 5'-ACCTTTTGTATAATGGG-3' & $23 \mathrm{~S}(553-569)$ & 23S sequencing \\
\hline $23 \mathrm{~S}-5^{\prime}-$-IIII & 5'-CAGTAAGTACTATCCGGGAG-3' & $23 \mathrm{~S}(912-931)$ & $23 \mathrm{~S}$ sequencing \\
\hline $23 \mathrm{~S}-3^{\prime}-\mathrm{II}$ & 5'-GCTCGAACCGTCATTCTC-3' & $23 \mathrm{~S}(2355-2340)$ & $23 \mathrm{~S}$ sequencing \\
\hline $23 \mathrm{~S}-3^{\prime}-\mathrm{III}$ & 5'-CTGTAGTAAAGGTTCACGG-3' & $23 \mathrm{~S}(2072-2054)$ & $23 \mathrm{~S}$ sequencing \\
\hline 23S-3'-IIII & 5'-GGTATCTGCGACTCTCGAC-3' & $23 \mathrm{~S}(2748-2730)$ & 23S sequencing \\
\hline $23 \mathrm{~S}-3^{\prime}-\mathrm{V}$ & 5'-CCTAGCCTTCTCCGTCCCC-3' & 23S (1427-1409) & $23 \mathrm{~S}$ sequencing \\
\hline Anti5S-5'-II & 5'-ATGCCTGGCGATGTCCTAC-3' & $5 \mathrm{~S}(120-102)$ & ITS2 and 5S amplification \\
\hline Anti 23S-3' & 5'-GAAAGCATCTAAGCGGGAA-3' & $23 \mathrm{~S}(2736-2754)$ & ITS2 and 5S amplification \\
\hline
\end{tabular}


according to the neighbor-joining method (Saitou \& Nei 1987) using ClustalW software (Thompson et al. 1994). The stability of the groupings was evaluated by performing a bootstrap analysis (1000 replications). A DNA distance matrix was calculated with the BioEdit Sequence Alignment Editor (Hall 1999).

Nucleotide sequence accession numbers. Photobacterium damselae sequences determined in the present study were assigned EMBL accession numbers as follows: P. damselae subsp. piscicida 5S gene (AJ274379), P. damselae subsp. damselae 23S gene (Y18520), subsp. piscicida 23S gene (Y17901), P. damselae subsp. piscicida ITS-2 (AJ250695, AJ250696), P. damselae subsp. damselae ITS-2 (AJ250697, AJ250698).

\section{RESULTS AND DISCUSSION}

\section{S rRNA gene sequence analysis}

A previous study (Osorio et al. 2000) showed that the 16S rRNA gene of Strain ATCC 29690 was nearly identical (only 1 nucleotide difference in the consensus sequence) to that of NCIMB 2058, which was used by Gauthier et al. (1995) to assign the taxonomic status of Photobacterium damselae subsp. piscicida. Strain ATCC 29690 is routinely used in our laboratory, and a greater amount of knowledge is available for this strain compared to the scarce genetic data we have from strain NCIMB 2058. Therefore, ATCC 29690 was included as a reference strain in this study in preference to NCIMB 2058.

Strains of Photobacterium damselae subsp. piscicida (ATCC 29690) and $P$. damselae subsp. damselae (ATCC 33539) were subjected to 23S rRNA gene amplification, yielding amplicons of ca. $3 \mathrm{~kb}$, and complete sequences of PCR products were determined. A 2892 nucleotide consensus sequence of the $23 \mathrm{~S}$ rRNA gene was obtained, showing 3 variable positions between the 2 subspecies of $P$. damselae (positions 1162, 2200 and 2217), which corresponds to a sequence similarity of $99.7 \%$. Sequence searches of the EMBL database revealed Vibrio vulnificus as the nearest relative (94\% identity). Other close relatives were $V$. splendidus $(93.8 \%$ identity), $V$. cholerae $(93.8 \%)$ and $V$. lentus $(93.5 \%)$.

When 23S PCR products were sequenced by primer walking, it was impossible to obtain a readable sequence in the vicinity of position 535, which was interpreted as microheterogeneity in gene size. Thus, PCR products were cloned and partially sequenced, showing that at least 1 chromosomal copy of the 23S rRNA gene has a single nucleotide deletion (of cytosine at position 535). Thus, variation was evident between different operons in the same chromosome, with lengths of 2892 and 2893 nucleotides. The 2 subspecies showed the same length-microheterogeneity pattern.

Although the 2 subspecies of Photobacterium damselae possess clearly different phenotypes, they show a 23S gene sequence similarity as high as $99.7 \%$, a situation similar to that reported for species of the genus Listeria (Sallen et al. 1996). A phylogenetic tree based on 23S rRNA genes was constructed in order to show the relationships of $P$. damselae with other taxa (Fig. 1). Similarity percentages in 23S gene sequences are smaller than those obtained with $16 \mathrm{~S}$ analysis in $P$. damselae (Osorio et al. 1999), indicating a higher number of variable residues in 23S. It has been reported that the similarity of $16 \mathrm{~S}$ rRNA genes is $4 \%$ higher than that of 23S rRNA genes in Proteobacteria (Ludwig et al. 1995) and there is agreement with data obtained for other bacterial taxa (Ludwig \& Schleifer 1994).

Results of 23S rRNA gene analysis show that Photobacterium damselae subsp. piscicida (formerly Pasteurella piscicida) is closely related to species of Vibrionaceae rather than to Pasteurellaceae, thus agreeing with results of DNA-DNA hybridization and 16S gene sequencing (Gauthier et al. 1995, Osorio et al. 1999).

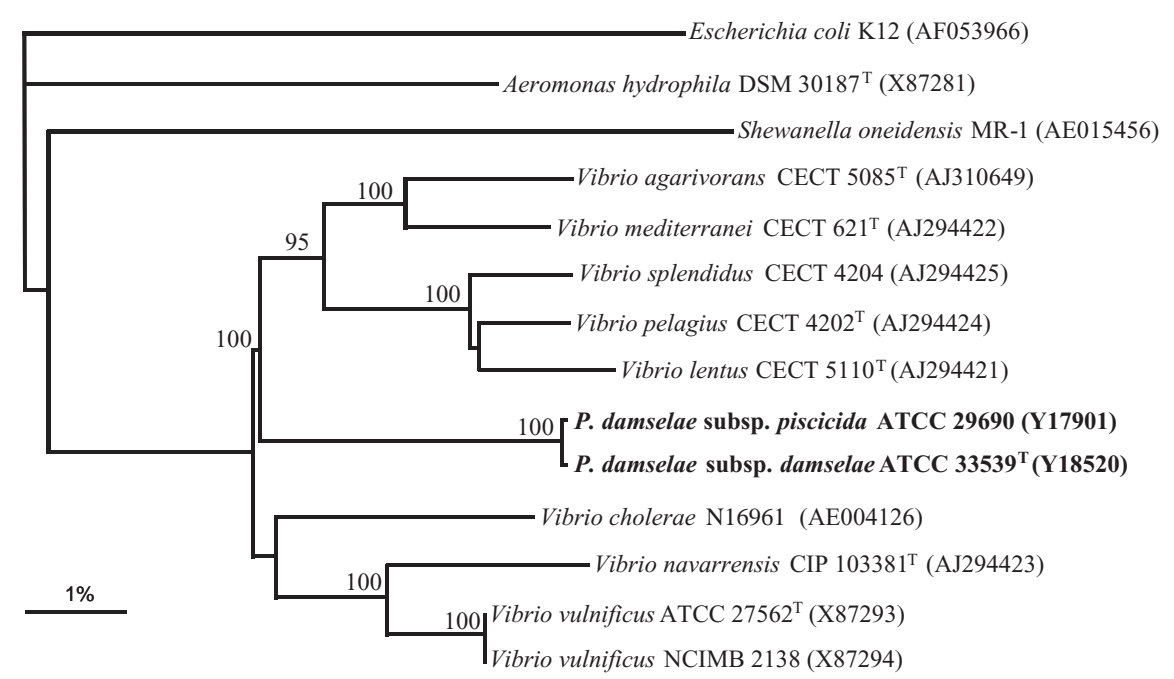

Fig. 1. Dendrogram showing phylogenetic relationships of Photobacterium damselae subspecies and some closely related species based on 23S rRNA gene sequences. The tree was constructed using the neighbor-joining method, and bootstrap values are expressed as percentages of 1000 replications (only those values above $80 \%$ are shown). Horizontal bar denotes the percentage sequence divergence 


\section{S rRNA gene}

The PCR products generated with Primers Anti23S3' and Anti5S-5'-II for subsp. damselae (Strains RG91 and ATCC 33539) and subsp. piscicida (Strains DI21 and ATCC 29690) were used for direct sequencing, so that a consensus sequence of the 5S rRNA gene was obtained. No base differences were found between the 4 strains. However, this consensus sequence differed in 4 nucleotide positions from that reported by MacDonell \& Colwell (1985) for Vibrio damsela ATCC 33539 (currently Photobacterium damselae subsp. damselae) (EMBL X02252). We attribute these differences to the intra-chromosomal microheterogeneity due to inter-cistronic variability, although differences in methodology in the different studies might also be the cause of the different consensus sequence obtained.

Sequencing of single 5S rRNA gene copies cloned in plasmid TOPO-TA revealed inter-cistronic variability affecting 8 positions in this gene (data not shown). Heterogeneity in $5 \mathrm{~S}$ gene sequence is frequent, and has been described between different strains of Escherichia coli (Brownlee et al. 1968).

A phylogenetic tree (Fig. 2) was constructed with 5S gene consensus sequences. The 2 subspecies of Photobacterium damselae formed a distinct group and did not cluster with other Photobacterium species. In addition, the similarity percentage between $P$. damselae and $P$. angustum $(90.0 \%)$ is clearly lower than that existing between $P$. angustum and most Vibrio species, such as $V$. fischeri $(96.7 \%)$ and $V$. logei (98.3).

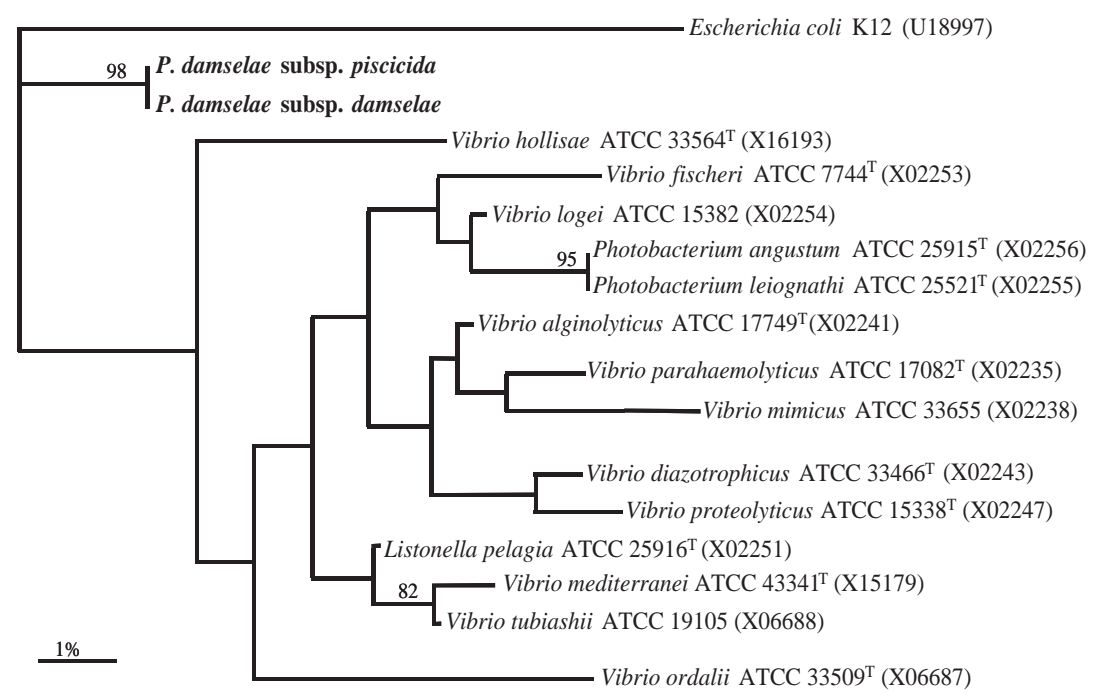

Fig. 2. Dendrogram showing phylogenetic relationships of Photobacterium damselae subspecies and some closely related species based on 5S rRNA gene sequences. Horizontal bar denotes the percentage sequence divergence
Since the beginning of molecular taxonomy, the study of the 5S rRNA gene sequence has been a minor task compared to the employment of $16 \mathrm{~S}$, as it was considered that the small $5 \mathrm{~S}$ molecule was more prone to evolutionary convergence (Woese 1982). Lane et al. (1985) pointed out that the mutational clock of the 5S molecule was slower than the average of the rest of the genome. In the tree constructed in our study, Photobacterium damselae is not grouped with $P$. angustum and $P$. leiognathi in a discrete cluster, an observation which has been reported previously (Nearhos \& Fuerst 1987). The fact that, on the basis of the $5 \mathrm{~S}$ gene, $P$. angustum and $P$. leiognathi seem to be synonymous (MacDonell \& Colwell 1985), whereas on the basis of the $16 \mathrm{~S}$ gene these 2 species are clearly distinguishable, supports the low accuracy of $5 \mathrm{~S}$ for phylogenetic studies, suggesting the susceptibility of 5S rRNA to undergo concerted evolution, as indicated by Woese (1982).

\section{Sequence analysis of ITS-2}

PCR amplification of Photobacterium damselae ITS2 regions with Primers Anti23S-3' and Anti5S-5'-II yielded products between 350 and $450 \mathrm{bp}$, and a slight difference in the fragment pattern of the 2 subspecies was observed (Fig. 3). PCR products were cloned using the TOPO-TA kit. A total of 93 clones were screened by EcoRI digestion, and different insert sizes were found for each strain (DI21: 30 clones, 3 different sizes; ATCC 29690: 22 clones, 3 sizes; RG91: 21 clones, 2 sizes; ATCC 33539: 20 clones, 2 sizes). The ITS-2 sequences were grouped into 4 different categories according to sequence sizes: 109, 158, 182 and $190 \mathrm{bp}$. Fig. 4 shows the sequence alignment of representatives of the 4 amplicon sizes, each belonging to one of the 4 strains studied. All the amplicons share the first $55 \mathrm{bp}$ at the $5^{\prime}$ end and the last $9 \mathrm{bp}$ at the $3^{\prime}$ end. Three of the 4 amplicons share a 71 bp sequence block close to the $3^{\prime}$ end, while the $109 \mathrm{bp}$ amplicon has a 45 bp block instead.

A feature found in these spacers, with the exception of the shortest one, is the existence of a sequence motif, ATCGAGTT, an octamer that is tandemly repeated 2,5 and 6 times. The molecular sizes of the 3 larger ITS-2 (158, 182 and $190 \mathrm{bp})$ are explained on the basis of the number of tandem repeats of this 


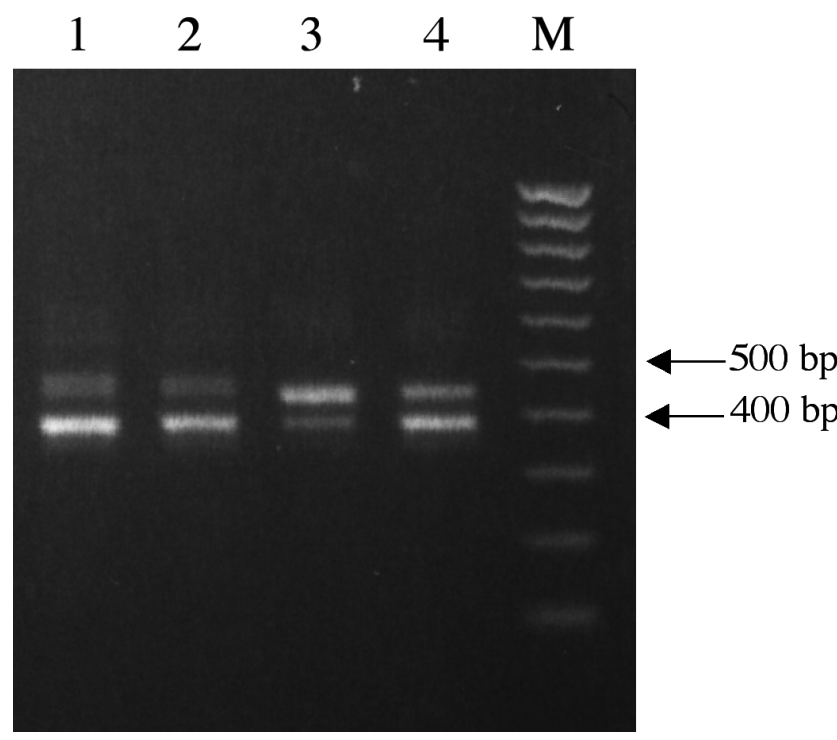

Fig. 3. Photobacterium damselae. Results of amplification of ITS-2 regions using primers Anti23S-3' and Anti5S-5'-II. Lane 1: Strain DI21; Lane 2: Strain ATCC 29690; Lane 3: Strain RG91; Lane 4: Strain ATCC 33539; M: molecular mass marker $(1 \mathrm{~kb})$

octamer. The presence of short repetitive sequences is a generalized feature in virtually all genetic systems. In a multigene family, such as the ribosomal genes including their spacer regions, this kind of phenomenon is more frequently observed, since recombination events may lead to the generation of new combinations of short repetitive sequences. In addition, strand slippage can occur during DNA replication, leading to either the duplication or the deletion of repetitive units.

A comparison of the 4 types of ITS- 2 amplicons shows that these sequences have a mosaic-like structure (Fig. 5). Amplicons of 182 and $190 \mathrm{bp}$ were found only in subsp. piscicida, in Strains ATCC 29690 and DI21 respectively. These 2 ITS-2 might explain in part the differential band pattern between subsp. piscicida and subsp. damselae observed in the PCR amplification (Fig. 3). The 109 and $158 \mathrm{bp}$ ITS-2 amplicons were found in all 4 strains tested. In addition, all the strains contain at least one of the 3 larger amplicons (of 158, 182 or $190 \mathrm{bp}$ ), which means that the main intra-specific variability is due to the number of tandem repeats of the octamer. All the other possible ITS-2 DNA sequence blocks (blocks of 55, 45, 71 and $9 \mathrm{bp}$ in Fig. 5) are present in all the strains. Each of the ITS-2 amplicon types are expected to occur in one or more copies in the chromosome, and this number of copies may vary between Photobacterium damselae strains, which would in part explain the difference in intensity of some PCR fragments (Fig. 3). For ITS-2 amplicons of 109 and $158 \mathrm{bp}$, inter- and intra-subspecies variation has been found as single nucleotide changes (data not shown). Percentage similarity in these 109 and $158 \mathrm{bp}$ amplicons ranged from $95.4 \%$ between strains of different subspecies to $100 \%$ between 2 strains of the same subspecies.

The DNA sequence of the 23S-5S spacer region of bacteria may provide information allowing discrimination between closely related taxa, which cannot otherwise be differentiated by rRNA gene sequences (Chen et al. 2000). The 2 ITS regions (16S-23S and 23S-5S spacer regions) are involved in the processing of primary rRNA transcripts to produce mature rRNAs (Srivastava \& Schlessinger 1990). Therefore, ITS sequences have highly conserved regions together with variable ones. In Photobacterium damselae ITS2 , major sequence variability occurs in the internal region of ITS-2, whereas sequence blocks covering the first 55 and the last 9 bp are conserved. A similar situation has been reported for example in Streptomyces species, where the 23S-5S ITS regions exhibited levels of sequence similarity of less than $50 \%$ with each other, while the first $23 \mathrm{bp}$ of each ITS-2 showed a sequence similarity higher than 95\% (Kim et al. 1993). The sequence lengths of $P$. damselae ITS2 regions are similar to those described in other bacterial species. For example, Lactobacillus shows ITS-2 sizes of 69, 71, 117 and $197 \mathrm{bp}$ (Nour 1998), and similar ITS-2 sizes have been reported in Propionibacterium species (Tilsala-Timisjärvi \& Alatossava 2001).

1 acaacaccca aggggtttta tcggactcca caacacttg aatgtaagtt acaacaccca aggggtttta tcggactcca caacacttg aatgtaagtt acaacaccca aggggtttta tcggactcca caacacttg aatgtaagtt acaacacca aggggtttta tcggactcca caacacttg aatgtaagtt

5

gttatcgagt atcgcgatag tcagttttta agattgtaac gttaggagtc gttatcgagt atcgcgatag tcagttttta agattgtaac gttaggagtc gttatcgagt atcgcgatag tcagttttta agattgtaac gttaggagtc

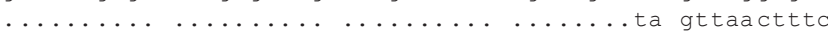
151

tcgtatcgag aatctcgac actcgtaacg aaaagaatt 190 tcgtatcgag aatctcgac actcgtaacg aaaagaatt 182 tcgtatcgag aatttcgac actcataacg aaaagaatt 158 ccagatt gct attt caagca cagcttgaaa taaacgaatt 109

Fig. 4. Photobacterium damselae. Sequence alignment of the 4 types of ITS-2 amplicon. DI21 and ATCC 29690, subsp. piscicida strains. RG91 and ATCC 33539, subsp. damselae strains. The tandem-repeated octamer is boxed, and repeated units are underlined 


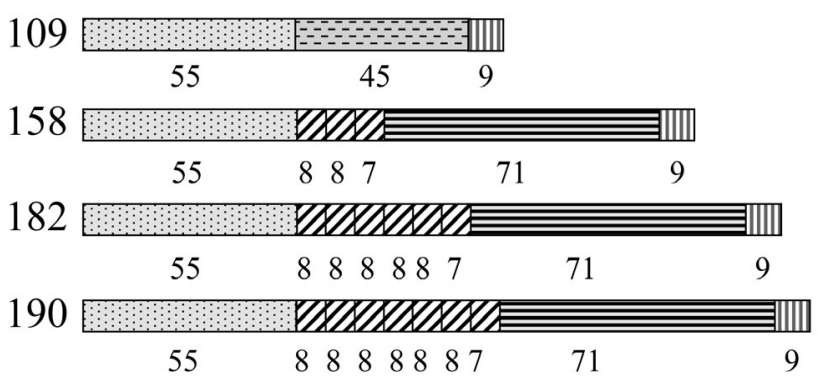

Fig. 5. Photobacterium damselae. Mosaic-like structure of ITS-2 spacers. Each type of shading indicates a different conserved sequence block. Numbers at the left indicate the length in nucleotides of each ITS-2 type. Numbers under the ITS-2 indicate the length of each sequence block

Bacterial species which have diverged recently may accumulate genetic differences in the chromosome, while that divergence may not be evident at the rRNA gene sequence level. In this sense, genetic variation has been previously reported between DI21 and ATCC 29690 strains by RAPD analysis (Magariños et al. 2000), and it has been proposed that these strains could belong to 2 different clonal lineages represented by the European and the Japanese isolates, respectively. However, in the present study, these 2 strains showed up to a $100 \%$ similarity in their ITS- 2 regions and, therefore, a geographical basis for the variation is not supported.

Thus, although the 2 subspecies of Photobacterium damselae share nearly the same consensus sequence of their $16 \mathrm{~S}, 23 \mathrm{~S}$ and $5 \mathrm{~S}$ genes, they may have undergone divergence in other genes, as a cause or consequence of their adaptation to different environments, particularly in that related to different host specificity. This could explain how these 2 subspecies are phenotypically so different, while still retaining a high similarity in their ribosomal operon DNA sequences. Further studies are necessary to help unravel the genetic events underlying the speciation of $P$. damselae subsp. damselae and subsp. piscicida.

Acknowledgements. This work was supported by grants MAR1999-0478 and ACU01-012, from the Ministerio de Ciencia y Tecnología (Spain).

\section{LITERATURE CITED}

Barry T, Colleran G, Glennon M, Dunican LK, Gannon F (1991) The 16S/23S ribosomal spacer region as a target for DNA probes to identify Eubacteria. PCR Methods Appl 1: 51-56

Brownlee GG, Sanger F, Barrell BG (1968) The sequence of 5S ribosomal ribonucleic acid. J Mol Biol 34:379-412

Buck JD, Overstrom NA, Patton GW, Anderson HF, Gorze- lany JF (1991) Bacteria associated with stranded cetaceans from the northeast USA and southwest Florida Gulf coasts. Dis Aquat Org 10:147-152

Chen H, Lim CK, Lee YK, Chan YN (2000) Comparative analysis of the genes encoding 23S-5S rRNA intergenic spacer regions of Lactobacillus casei-related strains. Int J Syst Evol Microbiol 50:471-478

Clarridge JE, Zighelboim-Daum S (1985) Isolation and characterization of two hemolytic phenotypes of Vibrio damsela associated with a fatal wound infection. J Clin Microbiol 21:302-306

Fouz B, Larsen JL, Nielsen B, Barja JL, Toranzo AE (1992) Characterization of Vibrio damsela strains isolated from turbot Scophthalmus maximus in Spain. Dis Aquat Org 12: 155-166

Gauthier G, Lafay B, Ruimy R, Breittmayer V, Nicolas JL, Gauthier M, Christen R (1995) Small-subunit rRNA sequences and whole DNA relatedness concur for the reassignment of Pasteurella piscicida (Snieszko et al.) Janssen and Surgalla to the genus Photobacterium as Photobacterium damsela subsp. piscicida comb.nov. Int J Syst Bacteriol 45:139-144

Gürtler V, Stanisich VA (1996) New approaches to typing and identification of bacteria using the 16S-23S rDNA spacer region. Microbiology 142:3-16

Hall TA (1999) BioEdit: a user-friendly biological sequence alignment editor and analysis program for Windows 95/98/NT. Nucleic Acids Symp Ser 41:95-98

Kim E, Kim H, Hong SP, Kang KH, Kho YH, Park YH (1993) Gene organization and primary structure of a ribosomal RNA gene cluster from Streptomyces griseus subsp. griseus. Gene 132:21-31

Lane DJ, Stahl DA, Olsen GJ, Heller DJ, Pace NR (1985) Phylogenetic analysis of the genera Thiobacillus and Thiomicrospora by 5S RNA sequences. J Bacteriol 163:75-81

Ludwig W, Schleifer KH (1994) Bacterial phylogeny based on 23S and 16S. FEMS Microbiol Rev 15:155-173

Ludwig W, Rosselló-Mora R, Aznar R, Klugbauer S and 13 others (1995) Comparative sequence analysis of 23S rRNA from Proteobacteria. Syst Appl Microbiol 18:164-188

MacDonell MT, Colwell RR (1985) Phylogeny of the Vibrionaceae, and recommendation for two new genera, Listonella and Shewanella. Syst Appl Microbiol 6:171-182

Magariños B, Toranzo AE, Romalde JL (1996) Phenotipic and pathobiological characteristics of Pasteurella piscicida. Annu Rev Fish Dis 6:41-64

Magariños B, Osorio CR, Toranzo AE, Romalde JL (1997) Applicability of ribotyping for intraspecific classification and epidemiological studies of Photobacterium damselae subsp. piscicida. Syst Appl Microbiol 20:634-639

Magariños B, Toranzo AE, Barja JL, Romalde JL (2000) Existence of two geographically-linked clonal lineages in the bacterial fish pathogen Photobacterium damselae subsp. piscicida evidenced by random amplified polymorphic DNA analysis. Epidemiol Infect 125:213-219

Morris JG Jr, Wilson R, Hollis DG, Weaver RE, Miller HG, Tacket CO, Hickman FW, Blake PA (1982) Illness caused by Vibrio damsela and Vibrio hollisae. Lancet 1:1294-1297

Nearhos SP, Fuerst JA (1987) Reanalysis of 5S rRNA sequence data for the Vibrionaceae, with the clustan program suite. Curr Microbiol 15:329-335

Nour M (1998) 16S-23S and 23S-5S intergenic spacer regions of lactobacilli: nucleotide sequence, secondary structure and comparative analysis. Res Microbiol 149:433-448

Osorio CR, Collins MD, Toranzo AE, Barja JL, Romalde JL (1999) 16S rRNA gene sequence analysis of Photobacterium damselae and nested PCR method for the rapid 
detection of the causative agent of fish pasteurellosis. Appl Environ Microbiol 65:2942-2946

Osorio CR, Toranzo AE, Romalde JL, Barja JL (2000) Multiplex PCR assay for ureC and 16S rRNA genes clearly discriminates between both subspecies of Photobacterium damselae. Dis Aquat Org 40:177-183

Pearson WR, Lipman DJ (1988) Improved tools for biological sequence comparison. Proc Natl Acad Sci USA 85: $2444-2448$

Saitou N, Nei M (1987) The neighbor-joining method: a new method for constructing phylogenetic trees. Mol Biol Evol 4:406-477

Sallen B, Rajoharison A, Desvarenne S, Quinn F, Mabilat C (1996) Comparative analysis of $16 \mathrm{~S}$ and 23S rRNA sequences of Listeria species. Int J Syst Bacteriol 46:669-674

Srivastava AK, Schlessinger D (1990) Mechanism and regulation of bacterial ribosomal RNA processing. Annu Rev Microbiol 44:105-129

Editorial responsibility: Carey Cunningham, Aberdeen, UK
Thompson JD, Higgins DG, Gibson TJ (1994) CLUSTAL W: improving the sensitivity of progressive multiple sequence alignment through sequence weighting, positions-specific gap penalties and weight matrix choice. Nucleic Acids Res 22:4673-4680

Thyssen A, Van Eygen S, Hauben L, Goris J, Swings J, Ollevier F (2000) Application of AFLP for taxonomic and epidemiological studies of Photobacterium damselae subsp. piscicida. Int J Syst Evol Microbiol 50:1013-1019

Tilsala-Timisjärvi A, Alatossava T (2001) Characterization of the $16 \mathrm{~S}-23 \mathrm{~S}$ and $23 \mathrm{~S}-5 \mathrm{~S}$ rRNA intergenic spacer regions of dairy propionibacteria and their identification with species-specific primers by PCR. Int J Food Microbiol 68: $45-52$

Woese CR (1982) Archaebacteria and cellular origins: an overview. Zentralbl Bakteriol (Naturwiss) C3:1-17

Woese CR (1987) Bacterial evolution. Microbiol Rev 51: $221-271$

Submitted: April 22, 2004; Accepted: July 2, 2004

Proofs received from author(s): October 1, 2004 